\title{
HVMANITAS
}

Solón y "Solón": el misterio de la poesía

Autor(es): $\quad$ González de Tobia, Ana María

Publicado por: Faculdade de Letras da Universidade de Coimbra, Instituto de Estudos

URL

persistente: URI:http://hdl.handle.net/10316.2/27909

DOI: $\quad$ DOI:http://dx.doi.org/10.14195/2183-1718_60_3

Accessed : $\quad$ 26-Apr-2023 10:39:05

A navegação consulta e descarregamento dos títulos inseridos nas Bibliotecas Digitais UC Digitalis, UC Pombalina e UC Impactum, pressupõem a aceitação plena e sem reservas dos Termos e Condições de Uso destas Bibliotecas Digitais, disponíveis em https://digitalis.uc.pt/pt-pt/termos.

Conforme exposto nos referidos Termos e Condições de Uso, o descarregamento de títulos de acesso restrito requer uma licença válida de autorização devendo o utilizador aceder ao(s) documento(s) a partir de um endereço de IP da instituição detentora da supramencionada licença.

Ao utilizador é apenas permitido o descarregamento para uso pessoal, pelo que o emprego do(s) título(s) descarregado(s) para outro fim, designadamente comercial, carece de autorização do respetivo autor ou editor da obra.

Na medida em que todas as obras da UC Digitalis se encontram protegidas pelo Código do Direito de Autor e Direitos Conexos e demais legislação aplicável, toda a cópia, parcial ou total, deste documento, nos casos em que é legalmente admitida, deverá conter ou fazer-se acompanhar por este aviso. 
humanitas

\section{Vol. LX}

IMPRENSA DA UNIVERSIDADE DE COIMBRA

COIMBRA UNIVERSITY PRESS 


\title{
SOLÓN Y "SOLÓN" EL MISTERIO DE LA POESÍA*
}

\author{
Ana María González de Tobia \\ Centro de Estudios de Lenguas Clásicas. Área Filología Griega \\ Universidad Nacional de La Plata. Argentina \\ amgontob@isis.unlp.edu.ar
}

\begin{abstract}
Resumen
Durante los últimos cinco años ha habido una excitante renovación del interés por la figura de Solón y su producción conservada y, por consiguiente, una plétora de estudios dedicados a su personalidad y a su obra. Las diferentes evaluaciones críticas otorgan una importancia destacable a Solón en la historia del pensamiento y vinculan su ideario a la concepción de que a una progresión del tiempo le corresponde necesariamente un progreso intelectual.

Si aplicamos la idea de la memoria social a los variados registros acerca de Solón, se pueden diseñar diferentes configuraciones de "Solón", todas ellas sostenidas a partir de sus propios fragmentos poéticos. La producción poética conservada y su función, podrían resumir, por lo tanto, un paradigma que responda a la denominación de "Solón" desde un ángulo esencialmente literario, poético.
\end{abstract}

Palabras clave: Solón, "Solón”, configuraciones, poesía.

\section{Abstract}

In the last five years, there has been a revival of interest in the figure of Solon and his remaining work. As a consequence, there emerged a plethora

\footnotetext{
* El texto de este artículo, con algunas modificaciones, corresponde a la conferencia dictada en oportunidad del XII Congreso Español de Estudios Clásicos, que se llevó a cabo en Valencia, entre los días 22 y 26 de octubre de 2007.
} 
of criticisms about his personality and work. Solon has been given an outstanding place in the history of thought. His ideas have been linked to the concept that a progress in time necessarily corresponds to a progress in thought. If the idea of "social memory" is applied to the different records about Solon, different configurations about "Solon" can be mentioned, all of which are sustained by his own poetic fragments. What remains of his poetry and its function could synthesize a paradigm that justifies the name "Solon", essentially, from a literary and poetic view-point.

Keywords: Solon, "Solon", configurations, poetry.

Solón es una de las figuras más importantes de la Grecia arcaica. La posteridad recuerda sobretodo tres aspectos de su poliédrica actividad: el de legislador, el de sabio y el de poeta. ${ }^{1}$

Los dos primeros aspectos de la personalidad soloniana han atraído la atención de los estudiosos mucho más que el tercero, el de poeta. El hombre de estado que promulgó una legislación y las reformas sociales de gran importancia y duración ha sido el centro de un vivo trabajo de investigación histórica en el curso del siglo XX, sobre todo después del descubrimiento y publicación del papiro londinense de la Constitución de los Atenienses aristotélica, en $1891 .^{2}$

Esto es lo que transforma a Solón en figura de gran relieve en la historia de la cultura griega y es real el hecho de que fue un gran poeta no menos que un reformador político y constitucional y que ejerció el medio de la poesía para comunicar ideas y opiniones, proyectos y apelaciones. Por lo tanto, es posible la rara oportunidad de vincular sus reformas legislativas y su moderación política, con las opiniones y otros objetivos que él mismo venía defendiendo en los poemas.

Sorprende y francamente disgusta observar que la poesía de Solón haya recibido una atención escasa de los estudiosos, durante la mayor parte del siglo XX, si tenemos en cuenta el interés que despertaron sus reformas políticas, sociales y legislativas. Sorprende también que ni siquiera sus

${ }^{1}$ Por motivo de espacio, las citas bibliográficas se limitarán, en su mayor parte, a las publicaciones más recientes, en las cuales el lector podrá encontrar las referencias a las obras críticas precedentes.

${ }^{2}$ Cf. Aristóteles. Constitución de Atenas, edición bilingüe de A. Bernabé 2005 y H. J. Gehrke 2006: 276-289. 
críticos más destacados hayan hablado del uso innovador de la lengua y la originalidad de su pensamiento. Consideramos que uno de los motivos de esta devaluación pudo ser, eventualmente, que Solón escribió en dísticos elegíacos, un metro que favorece el uso de frases y fórmulas homéricas. En efecto, él usa un vocabulario que es homérico o, al menos en general épico, y sus textos, por lo tanto su lenguaje y su estilo pueden parecer convencionales a un observador superficial. ${ }^{3}$

El estudio de la obra de Solón no escapó a la tendencia instalada en años recientes, que produjo un cambio radical en nuestra comprensión de la poesía Griega, desde el momento en que se comenzó a situar esta poesía en el contexto de la composición oral, de la performance oral y también de la transmisión oral. La teoría sobre una poética de la oralidad, que comenzó con la épica homérica, ${ }^{4}$ gradualmente se extendió a todo el campo de la poesía griega y ha tenido implicancias de largo alcance para los roles asignados a la audiencia; también para requerimientos de género y performance, culturalmente definidos, así como también para la autoría de los textos involucrados.

A partir de esta actitud, los estudios sobre Solón experimentaron un verdadero boom en los últimos años. La nueva edición para Loeb, realizada por Gerber en 1999; ${ }^{5}$ la excelente edición de Noussia, en 2001, con traducción y notas y la introducción de Herwig Maehler, ${ }^{6}$ así como la edición de Mülke, en 2002, con traducción y comentario de los poemas políticos de Solón 7 constituyen una contribución significativa a un fenómeno amplio de los volúmenes sobre el autor, que aparecieron hacia el fin del milenio.

El resultado se puede observar en las publicaciones de los últimos años, mediante autores como Almeida, Irwin, Lewis y Domínguez Monedero, en Latinoamérica, Maciel de Barros. ${ }^{8}$ Las fechas de estas publicaciones,

${ }^{3} \mathrm{Al}$ respecto, A. W. H. Adkins 1985: 1-33.

${ }^{4}$ G. Nagy, es, posiblemente, el mayor ejemplo de esta tendencia, en especial, para el tema que nos ocupa, su obra Pindar's Homer. The Lyric Possession of an Epic Past (1990).

${ }^{5}$ D. E. Gerber 1999.

"M. Noussia 2001.

${ }^{7}$ C. Miilke 2002.

${ }^{8}$ A. Domínguez Monedero 2001; J. A. Almeida 2003; E. Irwin 2005; J. Lewis 2006 y G. N. Maciel de Barros 1999. 
sin embargo, pueden ser indicadores engañosos porque algunas de estas obras son la culminación de tesis doctorales iniciadas en la segunda mitad de la década de los noventa (Noussia, en University College de Londres; Mülke, en Tubinga; Irwin y Lewis, en Cambrige y Maciel de Barros, en San Pablo), por lo tanto, demuestran que la tendencia comenzó antes, y se debió, sin duda a las magníficas ediciones de Gentili-Prato y de West. ${ }^{9}$ Pero Solón no permanece sólo como figura aislada y preservada únicamente por tesis doctorales últimas, sino que se constituye en un personaje al cual muchos han deseado regresar a lo largo de los estudios de disciplinas clásicas. Este sentimiento impulsó Josine Blok y André Lardinois a organizar la conferencia internacional sobre Solón, que tuvo lugar en Soeterbeeck, Holanda, en diciembre de 2003, cuyas contribuciones ya fueron publicadas. ${ }^{10}$ Estas colaboraciones, si se quiere numerosas, preanuncian un creciente interés sobre la obra de Solón y permiten garantizar una investigación futura muy interesante y controvertida sobre el poeta.

Podemos afirmar que los poemas de Solón han sido considerados la fuente primaria para la reconstrucción de la figura histórica de Solón, aún en la antigüedad.

Tenemos información más o menos detallada acerca de su vida, sobretodo de los principales testimonios y fragmentos, en Aristóteles, Diodoro Sículo, Plutarco, Diógenes Laercio. Sólo exiguas referencias se encuentran también en Heródoto, en Aristófanes y en los fragmentos de otros poetas cómicos. ${ }^{11}$ Resulta dificil otorgar certeza a estos testimonios, dada la tendencia de los biógrafos antiguos a extraer conjeturalmente de los textos de los poetas, informaciones y detalles sobre la vida de los poetas mismos. ${ }^{12}$ Es lícito dudar también, en el caso de Solón, de la credibilidad de lo que podrían ser solamente conjeturas.

Estas dudas resultan más lícitas aún, porque, por una parte, no es fácil comprender de qué materiales documentales pudieron servirse los antiguos,

${ }^{9}$ B. Gentili y C. Prato (eds.) 1988 y M. West (ed.) 1992. Las referencias a ambas ediciones en el artículo se harán mediante $\mathrm{G}-\mathrm{P}$ y W, respectivamente.

${ }^{10}$ J. H. Blok y A. P. M. H. Lardinois (eds.) 2006.

${ }^{11} \mathrm{La}$ reseña más actualizada y una síntesis de las fuentes antiguas acerca de la vida y obra de Solón, se encuentra en P. Oliva 1988.

12 Cf. J. A. Fairweather 1974: 231-75. 
para la información sobre Solón y sobre la Atenas de su tiempo, fuera de los fragmentos de Solón mismo. Por otra parte, sobre Solón florecen, probablemente, en el siglo VI y ciertamente en el V AC una serie de tradiciones legendarias que lo habían transformado en una especie de "héroe cultural". ${ }^{3}$

Ahora bien, si reconocemos que la mayor parte de nuestra poesía Griega arcaica ha sido pasada por el filtro de los períodos arcaico y clásico, antes de ser escrita y más o menos fijada de la manera que la conocemos hoy, particularmente en el caso de figuras de autoridad como Homero o Solón, debemos ser cuidadosos acerca de la manipulación de líneas y los cambios considerables que causó, sin dudas, la transmisión oral.

Aplicando la idea de la memoria social a las variadas referencias a Solón, podemos distinguir diferentes configuraciones de "Solón" cada una de ellas sostenida por sus poemas, que pertenecieron a diferentes grupos y sirvieron a diferentes intereses. ${ }^{14}$ Estas configuraciones que nos aportan un personaje, "Solón", responden en todos los casos a un hombre sabio y viajero, un legislador $\mathrm{y}$ un poeta vinculado siempre con el poder $\mathrm{y}$ sus contingencias.

La primera configuración de Solón aparece en Heródoto 1.29, ${ }^{15}$ quien llama a Solón, sofistes y dice que él les proporcionó leyes a los atenienses. Heródoto utiliza la figura de Solón para montar un encuentro paradigmático con el rey Creso, en el cual, el historiador contrasta las perspectivas del hombre cívico Griego y del rey del cercano Oriente. Aunque Heródoto no mencione específicamente ningún poema en este contexto, alude al fragmento $5 \mathrm{~W}$ (7 G-P) de Solón, sobre la vida humana.

Según Heródoto, el ateniense Solón visitó a Creso durante sus viajes, aún cuando Solón podría haber finalizado sus viajes 20 años antes de que Creso tomara el poder. La escena es la primera confirmación de un género popular en la literatura griega: el encuentro entre el sabio y el poderoso. Su propósito no es reproducir exactamente lo que ocurrió en el pasado, sino introducir los temas generales que plasmaron el esquema totalizador de los eventos. La narrativa de Heródoto está afectada por una simplicidad nada ingenua, por eso tergiversará los reclamos de la elite griega y aún

${ }^{13}$ Cf. M. R. Lefkowitz 1981: 46-48.

${ }^{14}$ Cf. E. Stehle 2006: 104-107.

${ }^{15}$ Hemos utilizado para el texto griego E. Legrand (ed.) 1993. 
cambiará el significado del concepto de olbos, "prosperidad", para lograr su propio final, tratando de dar una comprensión del término que hubiera irritado a la tradición del epinicio.

Según Heródoto, Creso recibió a Solón amablemente y ordenó a sus sirvientes que le brindaran una especie de tour por sus tesoros, para que comprobara por sí mismo la prosperidad del rey Lidio (1.30.1). Poco después Creso le preguntó a Solón quién era el hombre más olbios "próspero" (1.30.2) que él había visto en sus extensos viajes a través de la tierra, esperando, por supuesto, que Solón lo eligiera; pero Solón disgustó a Creso, porque le asignó el primer lugar a Tellos, un hombre ateniense. Cuando presentó al segundo, tampoco consideró a Creso, sino a dos hermanos argivos, Cleobis y Biton. Ambos eran jóvenes fuertes, con una adecuada riqueza y prosperidad material, eran dos atletas ganadores de primeros premios en los certámenes (1.31.1 aethlophoroi) que murieron en situación triunfo. ${ }^{16}$ Estos dos jóvenes atletas pođrian haber sido inmortalizados por Píndaro o Baquílides, si hubieran vivido un siglo después. ${ }^{17}$

El ateniense Tellos no poseía una gran riqueza material (1.30.1) ni poseía una reputación panhelénica. Mientras Cleobis y Bitón murieron jóvenes y, como Aquiles, ganaron fama, Tellos completó la otra opción del famoso destino de Aquiles, permaneciendo en su hogar, viviendo en una polis próspera hasta que llegó a ser abuelo (1.30.4). Sin embargo, Solón ubica a Tellos en primer lugar, antes que Cleobis y Biton y la narrativa de Heródoto marca un punto podríamos decir oblicuo respecto de los valores inscriptos en Píndaro y en Baquílides. Con menos posibilidad de ser distinguido por un epinicio estándar, 'Tellos, con su próspera familia y su muerte tardía luchando en una escaramuza, es, sin embargo, un ciudadano

${ }^{16}$ Sus jóvenes conciudadanos encargaron "estatuas de Cleobis y Biton en Delfos, con la dedicatoria que decía que ellos eran los mejores hombres" (1.31.5.). Las estatuas (que sorprendentemente, sobrevivieron y fueron descubiertas en una excavación francesa realizada en Delfos) cumplicron el mismo propósito que cumpliría después la poesía del epinicio: ambas estatuas y el poema servían para otorgar brillo a un evento particular en un medio artístico permanente que mantendría la atención por generaciones sucesivas.

${ }^{17} \mathrm{El}$ artículo más reciente que analiza la incorporación de este relato dentro del relato pertenece a Ch. Chiasson 2005: 41-64, donde el autor retoma, en algunos aspectos, su artículo anterior de 1986: 249-262. 
modelo de la polis. Una ciudad-estado colmada de hombres como Cleobis y Biton, que murieron jóvenes antes de que pudieran formar una familia, muy pronto desaparecería. Tellos reproduce en sí mismo, la seguridad de continuidad de su familia, y juega un rol importante en la tarea de mantener y sostener un estado.

Creso, preocupado sólo por sí mismo, obliga a Solón a explicar sus criterios para la asignación de puestos en este ranking. Solón expresa entonces una elaborada descripción de las innumerables vicisitudes que presenta la vida humana y culmina en el dictum "un ser humano es enteramente lo que a él le sucede" (1.32.20: pan esti anthropos sumphora) y se dirige a Creso con una explicación final de su criterio (1.32.5-7).

El debate entre Creso y Solón resuelve, por sí mismo, una diferencia acerca de la existencia humana. Creso pone el foco en la riqueza que ha acumulado y en la posición de poder que ha establecido para sí mismo; además asume -o Solón más tendenciosamente implica- que es en cierto sentido el dueño de su propio hecho y que su poder material le ha permitido ganar control sobre su vida. Para el Solón herodoteo, en definitiva, el ser humano no es una autónoma entidad autodefinida, sino un sujeto producido constantemente por eventos externos y acumulativos.

De acuerdo con lo que nos permiten juzgar los escasos fragmentos conservados de la poesía de Solón, Heródoto ofrece una airosa configuración de Solón.

El más estudiado fragmento conservado de Solón fr. 13 W (1 G-P) es una extensa discusión sobre la riqueza y su falta de permanencia de cara a las fuerzas que hay detrás del control mortal. Cuando el Solón de Heródoto apunta que "un ser humano es por completo lo que le sucede" (1.32.4), Heródoto mismo pudo haber estado dando una interpretación del este fragmento.

Aunque el encuentro entre Creso y Solón posiblemente nunca tuvo lugar, Heródoto "elabora" un Solón generalmente fiel al Solón que sobrevive en los fragmentos, y le otorga a este encuentro cierta verosimilitud y autoridad. En el relato de Heródoto, Solón es indirectamente responsable de la salvación de Creso, cuanto éste lo invoca en su circunstancia más extrema. Ciro siente curiosidad por lo que Creso está diciendo y Creso no sintió ansiedad por explicarlo. Sólo después de repetir la pregunta a través de los intérpretes de Ciro (1.86.25) (lipareoton auto) Creso eligió explicar que Solón le había hablado acerca de ólbos y la fragilidad de la fortuna humana y sólo después que Ciro escucha la lección de Solón y reconoce 
en Creso sobre la pira, una prueba de las afirmaciones de Solón decide perdonar a Creso. A su vez, recién cuando ve que Ciro está tratando sin éxito de apagar las llamas de la pira, el Creso de Heródoto invoca la charis del dios.

Creso, inicialmente, despreció a Solón y lo trató como a un tonto, pero más tarde, reconoció la profunda verdad de sus palabras. Heródoto construye su historia en torno de una transformación también, pero diferente, porque el Creso de Heródoto es transformado de un potentado en un sabio; ${ }^{18}$ es un mortal que ha cambiado riquezas y poder por sabiduría. Creso posee su grandeza no por obra de un dios, sino de Solón, cuyas palabras últimamente, lo rescataron y, más importante todavía, cambiaron su vida.

El rol ambivalente de la riqueza y la interpretación de la prosperidad y del poder se ubican en el centro de esta presentación. Heródoto ejerce la manipulación sobre el lenguaje para crear su acontecimiento y Solón es el eje de ese acontecimiento. ${ }^{19}$

El autor poético Solón tiene una mirada similar a la de su personaje herodoteo; pero su utilización lingüística está más cerca del Creso herodoteo.

Si nos atenemos a un segundo aspecto de las configuraciones de Solón, debemos considerar su inclusión en los denominados Siete sabios de Grecia.

Richard Martín, ${ }^{20}$ en un interesante y provocativo artículo, analiza desde el punto de vista antropológico y con el auxilio de los estudios comparativos, la compleja y particular construcción griega de la noción de sabiduría. La primera formulación, sería ¿Quién es llamado sabio? Y traslada esta pregunta a Grecia, en la época clásica. La respuesta inmediata puede ser, en esa instancia temporal, que sabios fueron los hombres sabios.

Ahora bien, resulta inquietante analizar por qué estos sabios, sofoi usualmente fueron establecidos en el número de siete, dentro de la visión histórico-folclórica y nos brindan una noción de gran influencia acerca de "sabiduría" tal como fue articulada en la cultura Griega antigua.

\footnotetext{
${ }^{18}$ Resulta interesante, al respecto, la explicación que proporciona Ch. Pelling
} 2006: 141-177.

${ }^{19}$ W. W. How y J. Wells 2002: 66 y 67.

${ }^{20}$ R. Martin 1993: 108-128. 
Hay aspectos dignos de interpretación acerca de la tradición de los Siete Sabios. Como punto de partida, podemos afirmar que la ubicación mitológica de este grupo respondió a valores culturales, por eso cada uno de ellos nos podrá responder, aunque en forma parcial, acerca de la mentalidad de la sociedad antigua. La mayoría de los cuatro o cinco Siete Sabios de Grecia son familiares. La posibilidad de nombrar siete, en cambio, presenta dificultades, porque por lo menos diecisiete nombres fueron incluidos alternativamente en la lista de los Siete Sabios.

Los Siete Sabios tuvieron en sus performances una audiencia muy selecta, tanto de griegos como de bárbaros.

La forma de sus máximas y su propia naturaleza nos llevan a pensar en un origen impersonal y, quizá, folclórico; sin duda cristalizaron en el molde de una cultura oral. Se trata de un material de atribución dudosa: los distintos autores no se ponen de acuerdo sobre su autor, a la hora de atribuir una máxima. Quienes nos hablan de las vidas de los Siete Sabios o nos ofrecen alguna información acerca de ellos padecen de una absoluta falta de sentido de la profundidad cronológica; nos han transmitido la visión que hoy tenemos de ellos como un grupo homogéneo, en el que, además, sus miembros fueron contemporáneos y tenían relaciones entre sí. En realidad, ni fueron contemporáneos ni, en consecuencia, pudieron en muchos casos mantener relaciones personales. Solamente cuatro (Tales de Mileto, Biante de Priene, Pítaco de Mitilene y Solón de Atenas) aparecen en todas las listas, los demás varían según la fuente.

Los Siete Sabios son personajes históricos, sin duda alguna -vivieron aproximadamente entre fines del siglo séptimo y mediados del sexto- y jugaron un papel de primer orden en la crisis que sacudió a Grecia por aquélla época. Habitantes de las ciudades más prestigiosas del Asia Menor y de Grecia continental reflejan un período connotado sobre todo por el surgir de la inteligencia política y jurídica.

Los Sabios, entre ellos Solón, confirieron una dimensión genuinamente política al sistema de oposiciones que caracterizan el período arcaico: impureza/purificación, obsesión/curaciones, locura/buen sentido.

Wilamowitz ${ }^{21}$ se refirió extensamente a un libro popular que no era propiedad exclusiva de nadie, al que la gente añadía las páginas que le gustaban, a medida que otras iban cayendo de viejas. La leyenda de los

${ }^{21}$ U. von Wilamowitz 1916: 396-439. 
Siete Sabios es producto de la necesidad imperativa de atribuir a alguien los dichos de carácter general.

Es en este punto que la configuración de Solón como uno de esos personajes adquiere connotación mitológica y se constituye en un antecedente muy importante para su aparición en alusiones posteriores, porque a partir de esta connotación, la figura de Solón, será tratada dentro de los límites imprecisos de la historia y la mitología, siempre adherida al poder de la sabiduría en contacto con la polis.

Platón es quien recupera y elabora esta configuración de Solón, en varios pasajes de su obra y añade un aspecto muy interesante, que es el de la valoración de Solón como poeta.

En Timeo 20e, ${ }^{22}$ Platón menciona a Solón como uno de los Siete Sabios y, más adelante, pone en boca de Critias un relato de su abuelo, que instala no sólo una valoración de Solón como poeta, sino también un Solón activo dentro del relato. Dice Critias, en Timeo21b-d: "Nuestros padres hicieron certámenes de recitación. Se declamaron poemas de muchos poetas y, como en aquella época los de Solón eran recientes, muchos niños los cantamos. Uno de los miembros de la fratría, ya sea que lo creía realmente o por hacerle un cumplido a Critias, dijo que si bien Solón le parecía muy sabio en todos los otros campos, en la poesía lo tenía por el más libre de todos los poetas. El anciano entonces - me acuerdo con claridad-se puso muy contento y sonriendo dijo: ¡Ay Aminandro! ¡Ojalá la poesía no hubiera sido para él una actividad secundaria! Si se hubiera esforzado como los otros, y hubiera terminado el argumento que trajo de Egipto y, si al llegar aquí, las contiendas civiles y otros males no lo hubieran obligado a descuidar todo lo que descubrió alli, ni Hesíodo ni Homero, en mi opinión, ni ningún otro poeta jamás habría llegado a tener una fama mayor que la suya". A continuación Platón hace ingresar a Solón, personaje, a cargo del relato sobre la Atlántida. ${ }^{23}$

Como podemos apreciar, Platón resulta un referente muy interesante, al configurar a Solón como sabio, político; pero sustancialmente, como un excelente poeta.

${ }^{22}$ Para el texto griego de Platón utilizamos la edición de I. Burnet 1982.

${ }^{23}$ A Timeo le sigue Critias cronológicamente. Resulta evidente que, en la vida del Creso de Heródoto y en la Atlántida, la voz autorizada para aleccionar es Solón. Una acertada explicación acerca de la importancia de Solón para la fundación platónica de la historia se encuentra en I. Costa 2007: 71-89. 
Desde el punto de vista poético, Solón se vincula estrechamente con la poesía de Homero y Hesíodo. ${ }^{24}$

La elegía manipuló y se apropió del hexámetro poético tradicional y de sus temas y los adecuó a las necesidades de su audiencia contemporánea. Solón se distingue por haber contextualizado con mayor éxito este género.

La elegía presenta una intersección entre la poesía arcaica y la política, mediante la denominada política de exhortación o parainesis. ${ }^{25}$ Los poetas elegíacos se dirigen a una audiencia inmediata, apelando a sus capacidades de ciudadanos de una polis, por lo tanto, se percibe, a través de las elegías conservadas, una sólida función cívica detrás de cada autor y de cada poema.

Los primeros poetas que propusieron este tipo de elegía fueron Calino y Tirteo y culminó el género con Solón, precisamente porque los antiguos y modernos tratamientos de sus fragmentos requirieron un método interpretativo que exigió una contextualización histórica.

Hay un lenguaje de Solón vinculado estrictamente con la tiranía, con el poder, que no sólo permite a Solón ocupar una posición distintiva y positiva con relación al demos, sino que también diseña una posición autocrática relacionada ambiguamente con la tiranía. ${ }^{26}$

Solón focaliza conceptos que superlativa y sugestivamente difieren de la tradición poética de la cual él, manifiestamente, ha demostrado ser heredero, nos referimos a las épicas de Homero y de Hesíodo. Solón, a su vez, transmite estos conceptos, a través de su poesía, y los vincula con una modalidad de la poesía lírica coral, que también manifiesta un compromiso socio-político y una sólida función de los autores, siempre incluidos en una contextualización histórica vinculada con el poder. ${ }^{27}$

${ }^{24}$ B. Graziosi 2002: 229-231, estudia la manera en la que Homero fue imaginado por los antiguos griegos. Dentro de esa circulación de historias se inscribe Solón, cuando produce una antigua recepción de los poemas homéricos en su obra. También E. Irwin, op. cit: 113-198 estudia la vinculación de la obra de Solón con Odisea y del fragmento 4 W, 3 G-P con Hesíodo, y K. Raaflaub 1993: 41-105.

${ }^{25}$ Cf. E. Irwin, op. cit., Part I: 15-82.

${ }^{26}$ Cf. E. Katz Anhalt 1993.

${ }^{27}$ Destacables conclusiones sobre la vinculación entre los fragmentos de Solón y el lenguaje de la tiranía se encuentran en E. Irwin, op. cit., III.7: 205-262 y en J. Lewis, op. cit: 108-130, entre otros. 
La poesía de la Grecia arcaica le otorgó voz a la historia y a la política de la cultura de su tiempo. La poesía de Solón desempeñó un papel fundamental en la articulación de las realidades e ideologías de su época y de su ciudad, de modo que ratifica la importancia del contexto como factor crítico para interpretar las expresiones políticas de la poesía.

El canto de la parainesis (exhortación, recomendación, consejo) elegíaca en el simposio de elite refleja la identidad del poeta con respecto a la comunidad de la polis, de modo que la identidad del poeta adquiere ribetes heroicos, y se expande y amplifica en la comunidad pública. ${ }^{28}$ Los fragmentos elegíacos de Solón confirman la práctica elitista y la subvierten, diseñando sobre las tradiciones poéticas de la épica homérica y hesiódica, una nueva propuesta que influyó no sólo sobre los poetas contemporáneos, sino, también sobre los sucesores, incluyendo los trágicos.

La relación de Solón con la poesía lírica coral del epinicio, por ejemplo, se establece a partir de conceptos esenciales para la configuración del poder político y social.

La poesía de Solón está inscripta en el contexto del pensamiento ético y político griego arcaico, explorando ambos los elementos tradicionales y revolucionarios de su poética. La originalidad y creatividad de Solón como poeta, la extensión de su contribución a los problemas, reposan en su concepto de comunidad, en su posición en la conciencia moral de los griegos, y en el universalismo de su programa político.

La diferencia entre poesía épica y poesía lírica, muy vasta, por cierto, necesita comprender que todos los poetas diseñaron sobre la poesía Homérica, que la poesía épica informó a la lírica. Si atendemos a los modos de la composición poética, vemos una significativa continuidad entre épica y lírica, y las técnicas compositivas propias de la oralidad, fueron también utilizadas en la poesía lírica tanto como en la épica. Cuando Solón compuso oralmente o por escrito, es imposible imaginar su creación sin asimilar y responder a la otra poesía de su período más antiguo, sin comprender el diseño de temas familiares y asociaciones y manipulaciones de esa poesía en sus resonancias y propósitos sociales.

Solón fue un fenómeno extraordinario que utilizó la poesía como principal medio de comunicación para agitar, advertir, enunciar y defender la política y sentó las bases de la Edad de Oro de Atenas.

\footnotetext{
${ }^{28}$ Cfr. E. L. Bowie 1986: 13-35.
} 
En el fragmento 36.6-7 W (30.6-7 G-P), Solón sintetiza un ideal eterno de vinculación entre su poesía y el concepto de poder, cuando, manifiesta: "yo le arranqué (a Atenas) los mojones clavados por muchas partes; porque antes era esclava y ahora es libre".

Notamos que, en los últimos tiempos, la tendencia crítica presenta dos novedades: por una parte, la discusión textual pormenorizada acerca de los fragmentos, para determinar la autoría cierta de Solón y por otra parte, la mención duplicada del poeta, como Solón y "Solón".

La primera situación arribó a su instancia más comprometida con el reciente artículo de Lardinois, cuyo título propone el gran debate. ${ }^{29}$

La segunda instancia surge, precisamente, de las sucesivas configuraciones de Solón que cada estudioso propone.

Según opinión de Raaflaub, ${ }^{30}$ en definitiva, si bien el poeta se servía naturalmente de las expresiones y del imaginario típico de la poesía yámbica y elegíaca de su tiempo y expresaba preocupaciones y temáticas relevantes para sus contemporáneos más o menos espacialmente vecinos, quien habla de manera inequívoca como un individuo bien determinado, un ateniense apasionado, un agudo pensador político, reformador convencido y progresista, es un hombre que se ubica en una posición media, metafóricamente, en la realidad, para rechazar la tiranía. A diferencia de otros poetas arcaicos, Solón no resulta "Solón".

A manera de aporte a este aspecto de la discusión, proponemos considerar a Solón como un logócrata, ${ }^{31}$ neologismo que tomamos a préstamo de George Steiner, quien, en su último libro, afirma que nuestra herencia, en cuanto a pensamiento y ética, nuestra lectura de la identidad y de la muerte, vienen de Sócrates y de Jesús de Nazareth y ninguno de los dos pertenece a la esfera de los autores, menos aún al circuito de la publicación. En toda la panoplia de las presencias de Sócrates en los diálogos de Platón y en las memorias de Jenofonte, no hay más que una o dos alusiones circunstanciales al uso de un libro. En cierto momento, Sócrates verifica las citas de un filósofo anterior, pidiendo que se le traiga el manuscrito en cuestión. Por lo demás, las enseñanzas de Sócrates y su

\footnotetext{
${ }^{29}$ A.P.M.H. Lardinois 2006: 15-35.

${ }^{30}$ K. Raaflaub 1996: 1053-81, en especial, p. 1042.

${ }^{31}$ G. Steiner 2007.
} 
destino ejemplar, tal como nos lo narra Platón o los evocan sucesores como Aristóteles, pertenecen al lenguaje hablado. No están escritos ni dictados.

Como Sócrates, Jesús ni escribió ni publicó. La única alusión de los Evangelios a un acto de escritura es la muy enigmática observación de Juan según la cual Jesús, en el episodio de la mujer adúltera, traza unas palabras en la arena. Nunca sabremos en qué lengua ni qué significaban, porque las borró enseguida.

Salvando las distancias, nosotros elaboramos hoy una síntesis de la figura de Solón, en su configuración máxima, que responde al diseño de este personaje poderoso, cuyo poder radica, precisamente, en el poder que tuvo su palabra, en el poder de la poesía y de la sabiduría y, esencialmente, en el amor por su ciudad. El Solón que nosotros hemos configurado es, definitivamente, Solón de Atenas y la Atenas que admiramos es la Atenas de Solón, por eso, acudimos, alternativamente a las denominaciones de Solón y "Solón", como una manera eficiente de salvaguardar nuestra apropiación de esos versos que parecen ser de Solón.

\section{Bibliografia}

A.W. H.Adxins (1985), Poetic Craft in the Early Greek Elegists. Chicago.

J. A. Almeida (2003), Justice an Aspect of the Polis Idea in Solon's Political Poems. A Reading of the Fragments in Light of the Researches of New Classical Archaeology. Leiden-Boston.

A. Bernabé (ed. y trad.) (2005), Aristóteles. Constitución de Atenas. Madrid. Edición bilingüe.

J. H. Blok y A. P. M. H. LARDinois (eds.) (2006), Solon of Athens. New Historical and Philological Approaches. Leiden-Boston.

E. L. Bowe (1986), "Early Greek Elegy, Symposium and Public Festival", JHS 106: 13-35.

I. Burnet (1982), Platonis Opera. Tomo IV. Oxford.

Ch. Chiasson (1986), "The Herodotean Solon", GRBS 27.3: 249-262.

CH. Chiasson (2005), "Myth, Ritual, and Authorial Control in Herodotus' Story of Cleobis and Biton (Hist. 1.31)", AJPH 126: 41-64.

I. Costa (2007), "Creso y Solón en el espejo de la Atlántida platónica", Synthesis 14: 71-89. 
A. Dominguez Monedero (2001), Solón de Atenas. Barcelona.

J. A. FarRWeather (1974), "Fiction in the Biographies of Ancient Writers", AncSoc 5: 231-275.

H.-J. Gehrke (2006), "The figure of Solon in the Athênaion Politeia", in J. H. Blok y A. P. M. H. Lardinois (eds.), Solon of Athens. New Historical and Philological Approaches. Leiden-Boston, 276-289.

B. Gentil y C. Prato (eds.) (1988), Poetae Elegiaci. Testimonia et Fragmenta. Leipzig.

D. E. Gerber (1999), Greek Elegy Poetry. Cambridge-MA-Londres.

B. GrazIost (2002), Inventing Homer. The Early Reception of Epic. Cambridge.

W.W. How y J.A Welis (2002), Commentary on Herodotus, V.I (Books I-IV). OxfordNew York.

E. IRWIN (2005), Solon and Early Greek Poetry. The Politics of Exhortation. Cambridge.

E. Katz Anhalt (1993), Solon the Singer. Politics and Poetics. Lanham.

A. P. M. H. Lardinois (2006), “Have we Solon's verses?”, in J. H. Blok y A. P. M. H. Lardinois (eds.), Solon of Athens. New Historical and Philological Approaches. Leiden-Boston, 15-35.

M. R. LeFkowitz (1981), The Lives of the Greek Poets. Londres.

E. Legrand (ed.) (1993), Hérodote. Histoires. Livre I. Paris.

J. LEwIS (2006), Solon The Thinker. Political Thought in Archaic Athens. Londres.

G. N. Maciel de Barros (1999), Solón de Atenas. A Cidadania Antiga. San Pablo.

R. MARtin (1993), "The Seven Sages as Performers of Wisdom", in C. Dougherty y L. Kurke (eds.), Cultural Poetics in Archaic Greece. Cambridge, 108-128.

C. MüLke (2002), Solons Politische Elegien und Iamben (Fr. 1-13; 32-37 West). Einleitung, Text, Übersetzung, Konmentar. Munich-Leipzig.

G. Nagy (1990), Pindar's Homer. The Lyric Possession of an Epic Past. Baltimore and London.

M. Noussia (2001), Solone. Frammenti dell' opera poetica. Milán.

P. Oriva (1988), Solon. Legende und Wirklichkeit. Constanza.

CH. Pelding (2006), "Educating Croesus: Talking and Learning in Herodotus' Lydian Logos", ClAnt 25: 141-177.

K. RaAflaub (1993), "Homer and Solon: The Rise of the Polis. The Written Sources", in M. H. Hansen (ed.), The Ancient Greek City-State (Symposium on the occasion of the 250 th Anniversary of the Royal Danish Academy of Sciences and Letters. July, 1-4 1992). Copenhague, 41-105.

K. RaAflaub (1996), "Solone, la nuova Atene e l'emergere della política en Diversità e unità del mondo greco", in S. Settis (ed.), I Greci. Storia, cultura, arte, società 2. Una storia greca I. Formazione. Turín, 1053-81. 
E. SteHLe (2006), "Solon's self-reflexive persona and its audience", in J. H. Blok y A. P. M. H. Lardinois (eds.), Solon of Athens. New Historical and Philological Approaches. Leiden-Boston, 79-113.

G. Steiner (2007, $2^{\mathrm{a}}$ ed.), Los logócratas, México.

U. Von Wllamowrtz (1916), Die Ilias und Homer. Berlín.

M. West (ed.) (1992), Iambi et elegi Graeci ante Alexandrum cantati II. Oxford. 